RU Особенности непрямого коммуникативного воздействия

\author{
адвоката и прокурора на жюри присяжных \\ во время судебного заседания \\ (на материале английских кинофильмов)
}

Илюхин Н. И.

\begin{abstract}
Аннотация. Цель исследования - доказать, что коммуникативное поведение адвокатов и прокуроров во время судебного заседания характеризуется наличием средств, используемых в рамках непрямого коммуникативного воздействия на жюри присяжных. Автор разграничивает понятия коммуникативного и речевого поведения. Научная новизна исследования заключается в том, что впервые на материале англоязычных кинофильмов проводится анализ суггестивной тактики адвоката и прокурора в рамках косвенного коммуникативного воздействия на присяжных. В результате доказано, что во время проведения допросов и перекрестных допросов адвокат и прокурор осуществляют коммуникативное воздействие на жюри присяжных через свидетелей посредством языковых средств, дискредитируя оппонента и его стратегию представления дела в суде.
\end{abstract}

\title{
EN Specificity of Defence Attorney's and Prosecutor's Indirect Communicative Influence on the Jurors during Trial (by the Material of English-Language Feature Films)
}

\author{
Ilyukhin N. I.
}

\begin{abstract}
The paper aims to prove that during a trial, a defence attorney and a prosecutor use the same communicative techniques to influence the jurors. The author differentiates the notions "communicative behaviour" and "verbal behaviour". Scientific originality of the study lies in the fact that the researcher for the first time analyses the suggestive tactics used by English-speaking defence attorneys and prosecutors to exert indirect verbal influence on the jurors. English-language feature films served as the research material. As a result, it is proved that during direct examination and cross-examination, defence attorneys and prosecutors use verbal manipulation techniques aiming to discredit the opponent and his trial strategy in the jurors' eyes.
\end{abstract}

\section{Введение}

Коммуникативное поведение адвоката и прокурора во время судебного процесса представляет собой на данном этапе развития языкознания противоречивое явление, поскольку существуют полярные мнения о том, частью какого типа дискурса оно является. Некоторые исследователи полагают, что коммуникативное поведение юристов может относиться к юридическому дискурсу, представляя собой один из его типов, характеризующийся фрагментарностью и неточностью, в то время как первый тип, будучи письменным дискурсом судей и юристов, может использоваться в качестве прецедента и играет знаковую роль в развитии юриспруденции [15, p. 2-3].

Другие ученые выделяют судебный дискурс как часть юридического и полагают, что коммуникация, реализуемая во время судебного процесса, должна рассматриваться в рамках этого дискурса (Т. Н. Астафурова, В. И. Карасик, М. Л. Макаров, Т. В. Дубровская).

А. В. Смирнов анализирует коммуникативное поведение юристов на судебном процессе в качестве нового дискурсивно-состязательного формирования, целью которого является обеспечение сторон не просто равными, но также достаточными возможностями для активной защиты законных интересов своих представителей $[10$, с. 150]. В данной работе коммуникативное поведение адвокатов и прокуроров во время судебного 
заседания рассматривается в контексте судебного дискурса, который, в свою очередь, представляет собой вербально-знаковое выражение коммуникации, возникающей во время судебного процесса, рассматриваемого в различных контекстах, в том числе национально-культурном и конкретном ситуативном, и учитывает намерения участников коммуникации [3, с. 34].

Таким образом, являясь неотъемлемым элементом судебного дискурса, коммуникативное поведение юристов представляет особый интерес для современного языкознания, поскольку позволяет проанализировать прагматические установки и инструменты, которые юристы используют в речи для достижения желаемого результата. Тем не менее на настоящий момент коммуникативное поведение адвокатов и прокуроров не является достаточно изученным явлением. Существуют отдельные работы, анализирующие суггестивные тактики поведения юристов во время судебного заседания, но комплексного анализа речи адвокатов и прокуроров, учитывающего все виды воздействия на жюри присяжных, а также все уровни коммуникации, проведено не было, несмотря на возрастающий интерес к образу юриста. Этим объясняется актуальность данной работы.

Кажется важным разграничить понятия «коммуникативное поведение» и «речевое поведение», поскольку данные термины часто используются синонимично. Речевое поведение представляет собой определяемые ситуацией общения эмоции, действия и поступки человека, выраженные с помощью языка и невербальных средств [1, с. 105]. И. А. Стернин рассматривает коммуникативное поведение личности как совокупность норм и ее традиций общения [11, с. 3]. В. И. Карасик, исследуя явление коммуникативного поведения, выделяет такие его неотъемлемые факторы, как ситуативность; наличие переносных смыслов, намеков, шуток; рациональность и эмоциональность произносимого; непосредственная связь с дискурсом [6, с. 264-268]. Коммуникативное поведение личности включает в себя не только вербальные и невербальные проявления той или иной личности в ситуации общения, но также и связь этой ситуации с другими коммуникативными актами, в которые эта личность была вовлечена.

Для достижения поставленной цели необходимо решить ряд задач:

1) описать особенности непрямого коммуникативного воздействия юриста на жюри присяжных;

2) на основе отобранного материала найти в коммуникативном поведении адвоката и прокурора языковые инструменты, косвенно воздействующие на присяжных;

3) провести анализ отобранных языковых инструментов, структурировать их и описать.

В качестве основных методов исследования использовались описательный и сопоставительно-описательный методы, в дополнение к которым привлекались методики компонентного, таксономического и количественного анализа речевого материала адвокатов и прокуроров. Компонентный метод исследования применялся при анализе лексических единиц в контексте тактики дискредитации оппонента; таксономический анализ использовался при структуризации найденных элементов в систему непрямого коммуникативного воздействия, а также отсеивании элементов прямого воздействия; количественный метод был необходим при подсчете найденных языковых приемов, использующихся при непрямом коммуникативном воздействии.

Материалом исследования послужили четыре англоязычных игровых кинофильма, а также два англоязычных телесериала, основной сценой которых является судебный процесс. Киноматериалы являются удобным средством анализа коммуникативного поведения адвокатов и прокуроров. Любой игровой кинофильм моделирует реальность, а разговорная речь героев обладает признаками реальной разговорной речи, а также имеет вербальное, невербальное и экстралингвистическое воплощение.

Теоретической базой исследования послужили труды отечественных языковедов, посвященные исследованию дискурса (В. И. Карасик), коммуникативного поведения (И. А. Стернин), судебного дискурса (Т. В. Дубровская, М. А. Зайцева, К. А. Устинова), суггестивных коммуникативных стратегий адвокатов и прокуроров (Т. С. Сафронова, Г. В. Кубиц), а также конфликтологии и теории конфликта (И. Н. Горелов, К. Ф. Седов).

Практическая значимость работы определяется перспективами использования полученных результатов в вузовских курсах по теории коммуникации, судебной лингвистике, а также создания отдельного курса по судебной прагматике.

\section{Особенности коммуникативного поведения адвокатов и юристов во время судебного процесса}

В своем коммуникативном поведении адвокаты и прокуроры прибегают к суггестивной тактике, направленной на жюри присяжных или на судью, поскольку от них зависит результат судебного процесса [5, с. 257]. 3десь суггестивная речевая стратегия понимается как «стратегия, направленная на побуждение суггерента (объекта воздействия) к реализации практических установок, необходимых суггестору» [9, с. 150]. Иными словами, адвокат и прокурор во время судебного заседания воздействуют на жюри присяжных для того, чтобы склонить их к желаемому для каждой из сторон решению. Г. В. Кубиц рассматривает виды речевого воздействия юристов, исходя из эксплицитности и имплицитности использованных ими речевых средств [8, с. 80]. Представляется, что анализ коммуникативного поведения юриста или прокурора должен отталкиваться от объекта речевого воздействия, т.е. жюри присяжных. В таком случае имеем два вида коммуникативного воздействия:

1) прямое воздействие, которое осуществляется в рамках непосредственного общения адвоката или прокурора с присяжными. К данному типу относятся прямые и заключительные речи юристов;

2) непрямое или косвенное воздействие на жюри присяжных, являющееся комплексным и сложным типом воздействия. К данному типу относятся все допросы и перекрестные допросы свидетеля, а также ситуации общения с судьей. 
Во время судебного заседания адвокат и прокурор существуют в контексте конфликта [4, с. 75]. Вслед за В. С. Третьяковой, речевой конфликт понимается как «состояние противоборства двух сторон (участников конфликта), в результате которого каждая из сторон сознательно и активно действует в ущерб противоположной стороне, эксплицируя свои действия вербальными и прагматическими средствами» [12, с. 127].

Одной из основных характеристик конфликта является наличие агрессии у одного или обоих участников конфликтной ситуации [2, с. 156]. Конфликтность продиктована особенностью судебного дискурса [13, с. 126]. В отличие от обычного речевого конфликта правовой конфликт более прагматичен. Любая эмоция, выраженная в речи юриста, продуцируется рационально. Основная цель такого рода конфликта в процессе судебного заседания - непрямое коммуникативное воздействие на членов жюри присяжных, которое, в свою очередь, выражается в виде тактики дискредитации оппонента и свидетеля.

\section{Тактика дискредитации оппонента}

Прокурор и адвокат, являясь конфликтующими сторонами в статусно-ориентированном дискурсе, вынуждены оспаривать мнение друг друга для того, чтобы воздействовать на жюри присяжных. Одним из распространенных приемов является тактика дискредитации оппонента. Под оппонентом в данном случае понимается юрист противной стороны:

- It's impossible to corroborate your evidence, because it's not true. You cannot corroborate something that didn't happen. / Невозможно подтвердить ваши доказательства, поскольку это неправда. Нельзя подтвердить то, чего не было.

- Objection! Is that a question or a form of abuse? / Протестую! Это вопрос или форма унижения?

- It's a form of abuse. / Это форма унижения [20] (здесь и далее перевод автора статьи. - Н. И.).

Прокурор, осуществляя перекрестный допрос подсудимого, обвиняемого в жестоком убийстве, пытается на него надавить, вызвав на эмоции, и окончательно разрушить стратегию защиты. Адвокат имеет право протестовать против высказанных обвинений, что он и делает. Все улики указывают на то, что подсудимый виновен, а защита лишь пытается замести следы, уводя подсудимых и манипулируя ими. Прокурор язвительно отвечает адвокату на его протест, хотя вопрос был задан судье и не касался стороны обвинения. Прокурор делает это намеренно, чтобы присяжные осознали, что у обвинения так много улик, что отрицать причастность и свою вину бессмысленно.

- Would you identify these photos, Captain Burke? / Вы узнаете эти фотографии, капитан Бюрк?

- Yes, sir, that's the Kensico Reservoir. / Да, сэр. Это водохранилище Кензико.

- Did you find any evidence at the scene that pertains to this case? / Вы нашли какие-либо улики на предполагаемом месте преступления?

- Yes, sir, we did. / Да.

- Then about here on the guardrail we found some strands of fabric. I believe they were stuck to some bird droppings. / На перилах мы нашли фрагменты ткани, они застряли в птичьем помете.

- Were you able to identify the fabric? / Вам удалось установить, что это за ткань?

- Yes, sir. It matched the fabric from Mrs. Strubing's sealskin coat. / Да. Фрагменты ткани совпали с котиковым пальто миссис Струбинг.

На этом прокурор заканчивает допрос своего свидетеля, а адвокат защиты начинает процедуру перекрестного допроса.

- Bird droppings? / Птичий помет?

- Sorry? / Простите?

- Birds droppings, Captain Burke? / Птичий помет, капитан Бюрк?

- Yes, that's right. / Да. Все верно.

- Were you able to identify the bird? / Вам удалость установить, что это за птица?

В зале послышались смешки [16].

В данном примере дело подсудимого, судя по уликам и несостыковкам в показании жертвы, является сфабрикованным. Адвокат защиты начинает перекрестный допрос свидетеля, сознательно «передразнивая» прокуpopa, используя его же реплику “were you able to identify”, но в совершенно ином, ироничном контексте. Таким образом, адвокат высмеивает нарочитый профессионализм прокурора, его линию защиты и уровень готовности стороны обвинения к делу. Смех в зале свидетельствует об успешности данного приема. Адвокат получил внимание присяжных и теперь может перейти к более серьезным вопросам, напрямую связанным с делом.

Помимо обвинений и столкновений, скрывающихся за иронией или абсурдом, в коммуникативном поведении адвокатов и прокуроров можно встретить открытое оскорбление противной стороны:

- The state opposes any request for bail. / Штат выступает против залога.

- Your honor, we haven't yet asked for bail. Now, the Governor Buckley cannot oppose a request until one is made. He should've learned that in law school. / Ваша честь, мы еще не просили о залоге. На данный момент сенатор Баклей не может выступать против залога, пока сторона защиты не сделала соответствующий запрос. Он должен был проходить это в университете.

- Everything that guy just said is bullshit. Thank you. / Все, что говорил вам тот парень, - это чушь собачья. Спасибо.

- Objection, Your Honor. / Протестую, Ваша Честь [17]! 


\section{Тактика дискредитации свидетеля}

Вынесение приговора присяжными во многом зависит от того, какая сторона убедит жюри в некомпетентности или лжи свидетелей противной стороны. Для этого юристы прибегают к различным инструментам непрямого воздействия на присяжных, вынуждая их не доверять показаниям свидетеля. Одной из самых эффектных тактик является сарказм или ирония. Данный прием представляет собой удобное средство, поскольку юристы находятся в контексте дискурса, роли и стилистика поведения участников которого строго определены. Сарказм позволяет выйти за рамки этих ограничений, поскольку его отличительной чертой является высмеивание ситуации или человека, используя высказывание с двойным смыслом [7, с. 102].

- You said that you were impressed and delighted with the quality of Andrew Beckett's work. Do you recall saying that? / Вы сказали, что были впечатлены и восхищены качеством работы Эндрю Бекетта. Вы помните, что говорили это?

- In all honesty, I was delighted with certain aspects of Andy's efforts. But in general, I found the work to be merely satisfactory. / Признаться честно, я был восхищен только определенными аспектами его работы, но в общих чертах я могу охарактеризовать его работу как удовлетворительную.

- Do you agree that a bologna sandwich is satisfactory meal, [laugh] whereas caviar and champagne, roast duck and baked Alaska, that might be considered a delightful meal? / Вы согласитесь с утверждением, что бутерброд с колбасой - это удовлетворительное блюдо, в то время как икра, шампанское, жареная утка и торт-безе могут быть классифицированы как восхитительное блюдо [18]?

Свидетель, в отношении которого ведется перекрестный допрос, был пойман на лжи. Ранее он писал в отчетах, а также утверждал, что подсудимый выполнял свою работу качественно и не совершил ни единого промаха, но на допросе он утверждает обратное. Адвокат защиты не желает просто сухо подчеркнуть факт искажения правды, поскольку он останется без внимания к концу слушания. Поэтому он прибегает к ироничной аллегории. Здесь под «колбасой» (“bologna sandwich”) подразумеваются новые показания свидетеля, в то время как «шампанское» (“champagne”), «жареная утка» (“roast duck”), «икра» (“caviar”), «торт-безе» (“baked Alaska”) предыдущие. Цель аллегории - иронично высмеять свидетеля и таким образом снизить уровень доверия к нему среди присяжных. Безусловно, адвоката не интересуют предпочтения свидетеля в еде. Приведенный гастрономический пример направлен на жюри присяжных и является понятным каждому человеку, независимо от образования, а также подчеркивает основную проблему данного свидетеля - лживые показания.

- What were you doing in Kielder forest, Mr. Berton? / Что вы делали в лесу Килдер, мистер Бертон?

- I had a job interview in Carlisle and a person I spoke to suggested that I tour around a bit. / Приехал на собеседование в Карлайл, работодатель посоветовал осмотреть окрестности.

- Do you normally conduct job interviews with a knife? / Вы обычно отправляетесь на собеседование с ножом [19]?

В данном примере прокурор желает совместить факт найденного орудия убийства у подсудимого и его показания о невиновности, ссылаясь на алиби, которое лишь косвенно может помочь ему избежать наказания. Вопрос, заданный прокурором, является риторическим, а слово «нож» (“knife”) придает вопросу ироничность, ведь реплика приобретает утвердительный характер. Прокурор обвиняет подсудимого в преступлении и лжи, а не интересуется положением дел.

Другим важным приемом дискредитации свидетеля является манипуляция. Адвокат строит вопросы таким образом, чтобы свидетель, отвечая на них, скомпрометировал сам себя. Коммуникативная манипуляция может быть двух видов: манипуляция фактами и эмоциональная манипуляция. В рамках первого типа манипуляции юристы задают череду вопросов, как правило, спокойно, размеренно, повторяя реплики свидетеля жюри присяжных, поскольку адвокатам важно, чтобы присяжные запомнили каждый ответ свидетеля. После этого юрист упоминает об определенном факте из биографии свидетеля, прямо или косвенно касающемся рассматриваемого дела. Факт при этом должен быть достоверным и компрометирующим все предыдущие ответы свидетеля. Таким образом, после ответа на последний вопрос свидетель уже не может располагать доверием присяжных:

- Doctor, have you ever been convicted of a felony? / Доктор, вас когда-нибудь обвиняли в совершении тяжкого преступления?

- No, of course not. / Конечно же, нет.

- You're certain? / Вы уверены?

- Yes. / Да.

- As certain of that as you are of the testimony you've just given before this jury? / Вы уверены в этом так же, как и в тех показаниях, которые вы ранее дали перед присяжными?

- Of course. / Конечно.

- You are telling me, and this jury, that on October 17th, 1960 you were not convicted of statutory rape? I have some mighty interesting photographs of you taken with a female underage in a motel by the Dallas Police Department on September 11th, 1960. Would you like to look at these images and see if they refresh your mетоry? / Вы хотите сказать мне и присяжным, что 17 октября 1960 года вас не обвиняли в изнасиловании? У меня тут есть очень интересные фотографии, сделанные полицией Далласа, на которых запечатлены вы и девочка-подросток в мотеле 11 сентября 1960 года. Не желаете ли взглянуть на них и освежить этот день в памяти? 
- No, I didn't think so. / Нет, думаю, нет.

- Now, doctor, I'm gonna ask you one last time were you or were you not convicted of statutory rape? / Теперь, доктор, я спрошу вас в последний раз: вы были обвинены в изнасиловании?

- Well, I can explain. / Я могу объяснить.

- Answer the question: yes or no. / Отвечайте на вопрос: да или нет.

- Yes. Yes, I was. / Да. Был [14].

В данном примере прокурор заранее знал о неприятном факте из биографии важного для защиты свидетеля - эксперта в области психиатрии. Прокурор тщательно продумал череду вопросов таким образом, чтобы предыдущие показания свидетеля после предоставления фактов и доказательств потеряли доверие среди присяжных. Свидетель до конца отрицал свою причастность к обвинению, но после фотографий уже не мог придерживаться старой стратегии. Для того чтобы усилить эффект на присяжных, прокурор специально задает вопрос по поводу предыдущих показаний свидетеля и их правдивости.

Тактика манипуляции эмоциями зачастую применяется адвокатом и прокурором в тех случаях, когда юрист подозревает свидетеля во лжи, но фактов, изобличающих эту ложь, на момент перекрестного допроса недостаточно или попросту нет. Речь юриста при этом характеризуется быстрым нарастающим темпом, или неожиданно для свидетеля адвокат или прокурор задает очень неудобный вопрос, на который свидетелю не хватает времени продумать ответ, поэтому он реагирует эмоционально:

- Mr. Hailey before you stepped outside yourself to watch yourself shoot Willard and Cobb were you aware that if convicted they might be freed in only ten years? / Мистер Хэйли, перед тем, как вы вышли из себя, чтобы посмотреть, как вы выстрелите в Вилларда и Кобба, осознавали ли вы, что они могут выйти из тюрьмы через десять лет?

- Yes, I heard people say that. Yes, sir. / Да. Я слышал, что люди говорили об этом.

- Do you think men who kidnap a child should be free in ten years? / Считаете ли вы, что человек, который похитил ребенка, должен быть освобожден через десять лет?

- No./Нет.

- Do you think men who rape a child should be free? / А мужчина, который изнасиловал ребенка, должен ли он быть на свободе?

- No, sir. / Нет, сэр.

- Do you think two men who hang a child should be free in ten years? / А двое мужчин, которые повесили ребенка, должны ли они быть осуждены только на десять лет?

- No. / Нет.

- What should happen? What would be fair? Do you think they deserve to die? / А что должно с ними произойти? Что будет честным? Может, они заслуживают смерти?

- Yes, they deserved to die and I hope they burn in hell! / Да. Они заслужили смерти, и я надеюсь, они горят в аду [Ibidem]!

Основная тактика защиты подсудимого, обвиняемого в двойном убийстве, строится на его невменяемости в момент совершения преступления. Прокурор понимает, что подсудимый лжет, поскольку убитые им мужчины за день до этого похитили и изнасиловали его дочь. Он осознает, что подсудимый совершил расправу, но присяжные питают к подсудимому симпатию, поэтому юрист пытается разрушить стратегию защиты, использовав эмоциональную манипуляцию: он специально задает вопросы, касающиеся дочери подсудимого, пауз между вопросами практически нет, громкость голоса с каждым вопросом повышается, тем самым оказывая давление на подсудимого, в итоге последний не выдерживает и признается, что желал смерти убитым им мужчинам, что свидетельствует о том, что он был полностью вменяем на момент совершения преступления.

\section{Заключение}

На основании проведенного исследования можно прийти к следующим выводам.

1. Во время судебного заседания адвокат и прокурор осуществляют непрямое коммуникативное воздействие на жюри присяжных во время допросов и перекрестных допросов свидетелей, не контактируя и не обращаясь к присяжным, в отличие от прямого воздействия, которое реализуется юристами через вступительную и заключительную речь.

2. В процессе осуществления непрямого воздействия на жюри присяжных адвокат и прокурор используют повторяющиеся коммуникативные тактики, направленные на свидетеля.

3. Самыми распространенными коммуникативными тактиками, реализуемыми юристами в рамках косвенного коммуникативного воздействия на присяжных, являются тактика дискредитации оппонента и свидетеля, которые, в свою очередь, строятся на таких языковых инструментах, как ирония, сарказм, манипуляция фактами, эмоциональная манипуляция, а также скрытое или прямое оскорбление противной стороны.

Перспективы дальнейшего исследования определяются более детальным исследованием каждого языкового инструмента и коммуникативной тактики, реализуемой в рамках непрямого коммуникативного воздействия на жюри присяжных, а также проведением комплексного анализа целостного коммуникативного поведения адвоката и прокурора, учитывая вербальный, невербальный уровни коммуникации и экстралингвистические особенности судебного процесса. 


\section{Источники | References}

1. Винокур Т. Г. Говорящий и слушающий: варианты речевого поведения. М.: КомКнига, 2005. 176 с.

2. Горелов И. Н., Седов К. Ф. Основы психолингвистики. М.: Лабиринт, 2010. 304 с.

3. Дубровская Т. В. Судебный дискурс: речевое поведение судьи: автореф. дисс. ... д. филол. н. Саратов, 2010.40 с.

4. Зайцева М. А. Судебный дискурс: речевые стратегии и тактики, языковые средства выражения конфликта // Перший незалежний науковий вісник. 2016. № 6 (6). Ч. 1. С. 74-78.

5. Илюхин Н. И. Особенности коммуникативного воздействия адвоката и прокурора на жюри присяжных во время судебного заседания (на материале английских кинофильмов) // Филологические науки. Вопросы теории и практики. 2020. Т. 13. Вып. 9. С. 256-261.

6. Карасик В. И. Языковые ключи. М.: Гнозис, 2009. 406 с.

7. Костыгова А. С. Лингвопрагматические и стилистические особенности высказываний с саркастическим смыслом // Известия Российского государственного педагогического университета им. А. И. Герцена. 2013. № 160. С. 101-107.

8. Кубиц Г. В. Стратегия речевого воздействия адвоката в судебном процессе // Вестник Челябинского государственного университета. Филология. Искусствоведение. 2011. № 33 (248). Вып. 60. С. 80-82.

9. Сафронова Т. С. Механизмы суггестивного воздействия во вступительной речи адвоката (на материале английского языка) // Филологические науки. Вопросы теории и практики. 2017. № 6 (72). Ч. 2. С. 149-153.

10. Смирнов А. В. Реформы уголовной юстиции конца XX века и дискурсивная состязательность // Журнал российского права. 2001. № 12. С. 145-155.

11. Стернин И. А. Модели описания коммуникативного поведения. Воронеж: Гарант, 2000. 27 с.

12. Третьякова В. С. Конфликт глазами лингвиста // Юрислингвистика-2: русский язык в его естественном и юридическом бытии. Барнаул: Изд-во Алт. ун-та, 2000. С. 127-140.

13. Устинова К. А. Институциональные признаки судебного дискурса // Вестник Челябинского государственного университета. Филология. Искусствоведение. 2011. № 33 (248). Вып. 60. С. 125-127.

14. A Time to Kill / directed by J. Chumacher. The USA, 1996.

15. Conley J. M., O’Barr W. M. Rules versus Relationships: The Ethnography of Legal Discourse. Chicago - L.: University of Chicago Press, 1990. 222 p.

16. Marshall / directed by R. Hudlin. The USA, 2017.

17. My Cousin Vinny / directed by J. Lynn. The USA, 1992.

18. Philadelphia / directed by J. Demme. The USA, 1993.

19. The Escape Artist. Part 3. The UK, 2013.

20. Your Honor. Part ten. The USA, 2021.

\section{Информация об авторах | Author information}

RU Илюхин Никита Игоревич ${ }^{1}$, к. филол. н.

${ }^{1}$ Саратовская государственная юридическая академия

EN Ilyukhin Nikita Igorevich ${ }^{1}, \mathrm{PhD}$

${ }^{1}$ Saratov State Law Academy

${ }^{1}$ tringla@mail.ru

\section{Информация о статье | About this article}

Дата поступления рукописи (received): 31.03.2021; опубликовано (published): 31.05.2021.

Ключевые слова (keywords): судебный дискурс; непрямое коммуникативное воздействие; речь адвоката; речь прокурора; суггестивная функция; juridical discourse; indirect communicative influence; defence attorney's speech; prosecutor's speech; suggestive function. 